\title{
Dynamism, Sensitivity, and Consequences of Mesenchymal and Stem-Like Phenotype of Cancer Cells
}

\author{
Petra Gener (D), ${ }^{1,2}$ Joaquin Seras-Franzoso, ${ }^{1}$ Patricia González Callejo, ${ }^{1,2}$ \\ Fernanda Andrade, ${ }^{1,3,4}$ Diana Rafael, ${ }^{1,2}$ Francesc Martínez, ${ }^{1}$ Sara Montero, ${ }^{1,2}$ Diego Arango, ${ }^{5}$ \\ Joan Sayós, ${ }^{6}$ Ibane Abasolo, ${ }^{1,2,7}$ and Simó Schwartz Jr. (iD) \\ ${ }^{1}$ Drug Delivery and Targeting Group, CIBBIM-Nanomedicine, Vall d'Hebron Institut de Recerca (VHIR), Vall d'Hebron Barcelona \\ Hospital Campus, 08035 Barcelona, Spain \\ ${ }^{2}$ Networking Research Center on Bioengineering, Biomaterials and Nanomedicine (CIBER-BBN), 08035 Barcelona, Spain \\ ${ }^{3}$ I3S-Instituto de Investigação e Inovação em Saúde, Universidade do Porto, Porto, Portugal \\ ${ }^{4}$ INEB-Instituto de Engenharia Biomédica, Universidade do Porto, Porto, Portugal \\ ${ }^{5}$ Biomedical Research in Digestive Tract Tumors, CIBBIM-Nanomedicine, Vall d'Hebron Institut de Recerca, Universitat Autonoma \\ de Barcelona, Barcelona, Spain \\ ${ }^{6}$ Immune Regulation and Immunotherapy, CIBBIM-Nanomedicine, Vall d'Hebron Institut de Recerca, Universitat Autonoma \\ de Barcelona, Barcelona, Spain \\ ${ }^{7}$ Functional Validation and Preclinical Research (FVPR), CIBBIM-Nanomedicine, Vall d'Hebron Institut de Recerca, \\ Universitat Autonoma de Barcelona, Barcelona, Spain
}

Correspondence should be addressed to Simó Schwartz Jr.; simo.schwartz@vhir.org

Received 29 June 2018; Accepted 17 August 2018; Published 10 October 2018

Academic Editor: Roberta Fusco

Copyright (C) 2018 Petra Gener et al. This is an open access article distributed under the Creative Commons Attribution License, which permits unrestricted use, distribution, and reproduction in any medium, provided the original work is properly cited.

There are remarkable similarities in the description of cancer stem cells (CSCs) and cancer cells with mesenchymal phenotype. Both cell types are highly tumorigenic, resistant against common anticancer treatment, and thought to cause metastatic growth. Moreover, cancer cells are able to switch between CSC and non-CSC phenotypes and vice versa, to ensure the necessary balance within the tumor. Likewise, cancer cells can switch between epithelial and mesenchymal phenotypes via well-described transition (EMT/MET) that is thought to be crucial for tumor propagation. In this review, we discuss whether, and to which extend, the CSCs and mesenchymal cancer cells are overlapping phenomena in terms of mechanisms, origin, and implication for cancer treatment. As well, we describe the dynamism of both phenotypes and involvement of the tumor microenvironment in CSC reversion and in EMT.

\section{Differences and Similarities of Mesenchymal and Stem-Like Phenotypes of Cancer Cells}

Our understanding of cancer biology and genetics has changed sustainably over the past 10 years. We consider tumor to be a highly complex heterogenic dynamic entity that evolves in time, always trying to adapt and survive to adverse conditions. For example, in order to survive to multimodal therapy, which includes resection, chemotherapy, and radiation, tumor cells undergo dynamic clonal evolution. As a result, tumors become a mass of highly heterogeneous cell populations undergoing constant dynamic phenotypic changes [1]. In addition, somatic mutations and phenotypic variations might generate cancer cell clones that develop resistance to treatment and remain progressing while current treatment eliminates only sensitive clones. In fact, a tumor may initially shrink after multimodal treatment, while remaining resistant clones which will survive 


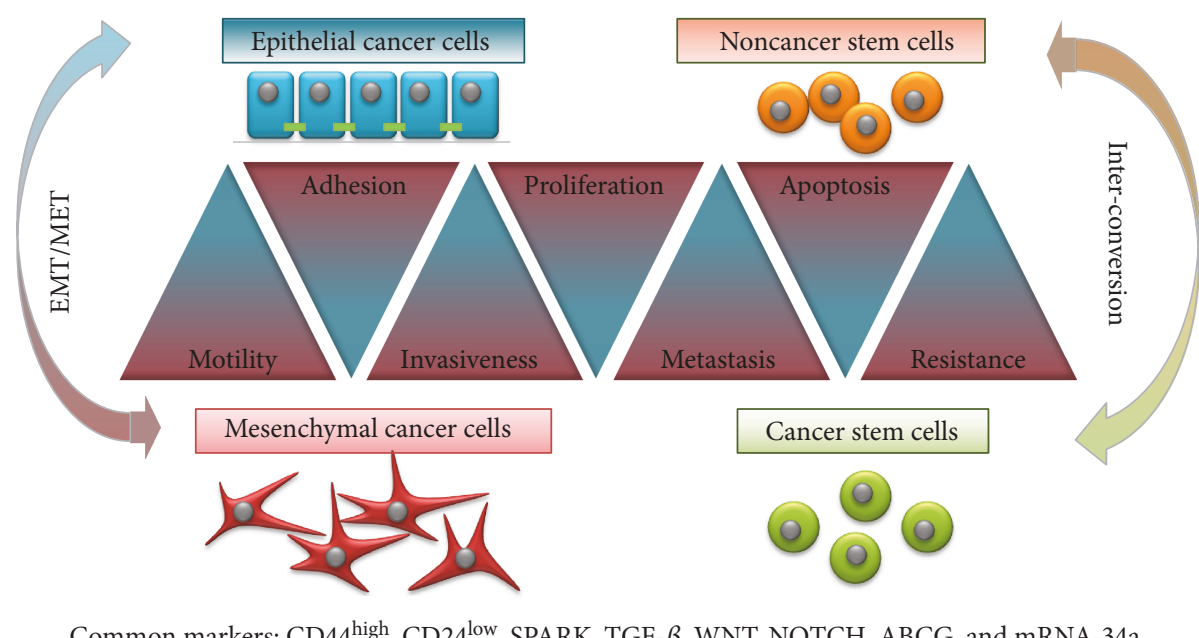

FIGURE 1: Cancer stem cells versus mesenchymal cancer cells. There are remarkable similarities in the properties of CSCs and cancer cells with mesenchymal phenotype, which oppose from characteristics of non-CSCs and epithelial cancer cells, respectively. Both are highly invasive, tumorigenic, resistant against common anticancer treatment, and thought to cause metastatic growth. Both cell types share several cell markers. Besides, both phenotypes are reversible and can be interchanged via EMT or CSC phenotype interconversion.

and eventually cause tumor regrowth and relapse, often rising very aggressive tumor types with unfortunately very limited treatment alternatives $[2,3]$.

Notably, tumors from patients with recurrent resistant tumors show higher numbers of CSCs and cells with epithelial-mesenchymal transition (EMT) phenotype. Indeed, poor survival has been associated with the presence of both cell types in various clinical trials [4].

CSCs represent a fraction of undifferentiated cancer cells that exhibit stem cell-like features. They have the ability to differentiate and to self-renew. Owing to the phenotypic differences with the rest of tumoral cells, CSCs account for therapy resistance and represent the cellular reserve responsible for tumor regrowth and metastatic spread [5]. CSCs overexpress ATP-dependent drug efflux transporters like Pglycoprotein (P-gp), the multidrug resistance-associated proteins (MRP), and ATP-binding cassette (ABC) transporters at the cell surface, which decrease intracellular drug accumulation. Besides, detoxifying enzymes like aldehyde dehydrogenase 1 (ALDH1A1) and bleomycin hydrolase (BLMH) provide CSCs with further protection against chemotherapy. CSCs are able to enter to a stable quiescence state in hypoxic conditions, overpass the stress condition, and proliferate afterwards [5]. In the last years, many research groups employed big efforts in order to identify biomarkers which could specifically characterize the different subpopulations of CSCs within a tumor [6]. Interestingly, most of the identified CSC markers can be also found in cells with mesenchymal phenotype $\left(\mathrm{CD} 44^{+} / \mathrm{CD} 24^{-}\right.$, SPARK, WNT, NOTCH, ABCG, mRNA-34a, etc.). Moreover, the characterization of cancer cells, which have acquired mesenchymal features by EMT, is quite similar to the description of CSCs (Figure 1). EMT cells are essential for tumor progression, including tumor metastasis, therapy resistance, and disease recurrence. A majority of tumors (90\%) are epithelial in nature (carcinomas); therefore, the activation of an EMT program, which originally plays a crucial role in organogenesis during embryonic development as well as wound healing and tissue regeneration, can transform epithelial cancer cells into a more aggressive mesenchymal phenotype, promoting local invasion and dissemination at distant organs [7].

During EMT, epithelial cells lose their cell-cell adhesion and apical-basal polarity, gaining the ability to individually migrate and invade basement membrane and blood vessels [7]. This conversion correlates with a decrease in epithelial markers (E-cadherin, cytokeratin, integrin $\alpha 6 \beta 4$, laminins, collagen type IV, ZD-1, etc.) and an increase in mesenchymal markers ( $\mathrm{N}$-cadherin, vimentin, fibronectin, cadherin-11, integrin $\alpha 5 \beta 1$, collagen types I and III, etc.) [8-11]. Interestingly, several recent studies pointed out an increase in CSC signature during EMT processes in many carcinomas such as pancreatic, hepatocellular, and colorectal as well as in human mammary epithelial cells [12-15] (Figure 2).

Even though in the past CSCs and EMT were studied independently, accumulating evidence suggests strong parallelisms between EMT activation and CSC formation. EMT is relevant to the acquisition and maintenance of stem cell-like characteristics and is sufficient to endow differentiated normal and cancer cells with stem cell properties. Recently, proteasome activator subunit 3 (PSME3) has been shown to induce epithelial-mesenchymal transition of breast cancer cells together with induction of CSC marker expression and further to influence the tumor immune microenvironment [16]. Moreover, CSCs often exhibit mesenchymal properties within epithelial tumor cells $[6,7,15,17-20]$. Most likely, heterogeneous cancer cell subpopulations, including CSCs and cells with activated EMT signaling, function in a complementary manner at the collective level to achieve therapeutic resistance and ensure disease progression. The idea of tumors as a highly dynamic heterogeneous mass of cells with an unstable and reversible hierarchy, which seems to be influenced by the origin and biological context of each tumor, is gaining acceptance. According to this scenario, a new concept of tumor plasticity, an "EMT score," has been proposed 


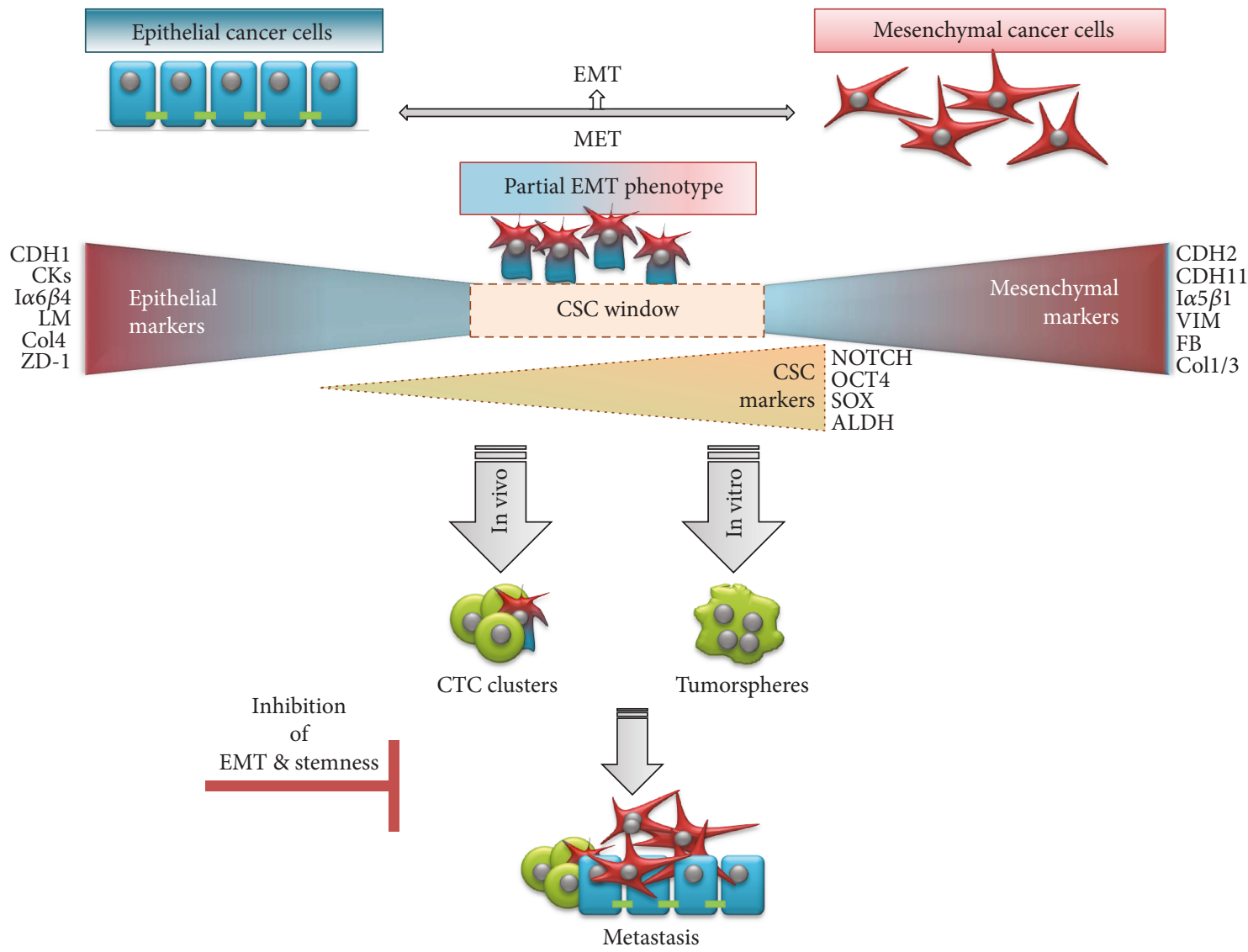

FIGURE 2: E/M hybrid phenotype. E/M hybrid phenotype of tumor cells represents an ideal window for stemness reversion. In this state, cancer cells coexpress epithelial and mesenchymal genes and promote expression of stemness genes. This results in formation of a tumor sphere in vitro and metastatic spread in vivo. Also, a majority of circulating cancer cell (CTC) clusters coexpress epithelial and mesenchymal markers together with stem cell markers. An inhibition of EMT and/or stemness phenotype should lead to hindrance of advanced cancer.

to represent the EMT-grade characteristic of each cell line and primary tumor $[14,21]$. Tan and colleagues established a universal and quantitative EMT scoring to define an EMT spectrum across various cancers (ovarian, breast, bladder, lung, colorectal, and gastric cancers) $[14,21]$. Tumorspecific gene expression was used to establish an EMT scoring method and quantitatively estimated the degree of EMT $(-1.0$ to +1.0$)$ in a large collection of cell lines and tumors, reflecting epithelial and mesenchymal states as well as the intermediate states that occur during transition. Good correlation between EMT and poorer disease-free survival was observed in ovarian and colorectal cancers, but not in breast cancer or carcinomas. Importantly, a distinct response between epithelial and mesenchymal-like ovarian cancers to therapeutic regimes administered with or without paclitaxel in vivo was also observed $[14,21]$.

Of note, the observed intermediate, mixed epithelial and mesenchymal phenotype (E/M hybrid phenotype), is thought to represent the ideal window for stemness reversion [18, 22, 23] (Figure 2). This theory is supported by the fact that repression of EMT is required for effective tumor initiation [24-27] and that CSC reprogramming often involves mesenchymal to epithelial transition (MET) $[28,29]$.
Further, coexpression of epithelial and mesenchymal genes promotes mammosphere formation and expression of stemness genes [22] and drives tumor growth in vivo $[18,23]$. Besides, according to mathematical models of stemness-decision circuits, it has been suggested that a hybrid $\mathrm{E} / \mathrm{M}$ state is more likely to gain stemness than complete EMT is $[14,30]$. These observations are consistent with experiments showing that a majority of circulating cancer cells (CTCs) coexpress epithelial and mesenchymal markers together with stem cell markers [31]. CTCs in a semimesenchymal phenotype have higher proliferative and invasive abilities than cells with complete EMT phenotype and are able to originate distant metastasis $[32,33]$ (Figure 2). The association of a hybrid E/M phenotype with stemness is not specific to tumor progression but has been also reported in physiological conditions in adult hepatic stem/progenitor cells (HSCs) and adult renal progenitors upon tissue injury and show to mediate tissue repair and regeneration [34-36].

\section{Dynamic Cancer Cell Phenotype}

There is increasing evidence showing that some cell subpopulations are subjected to a dynamic phenotype within a 


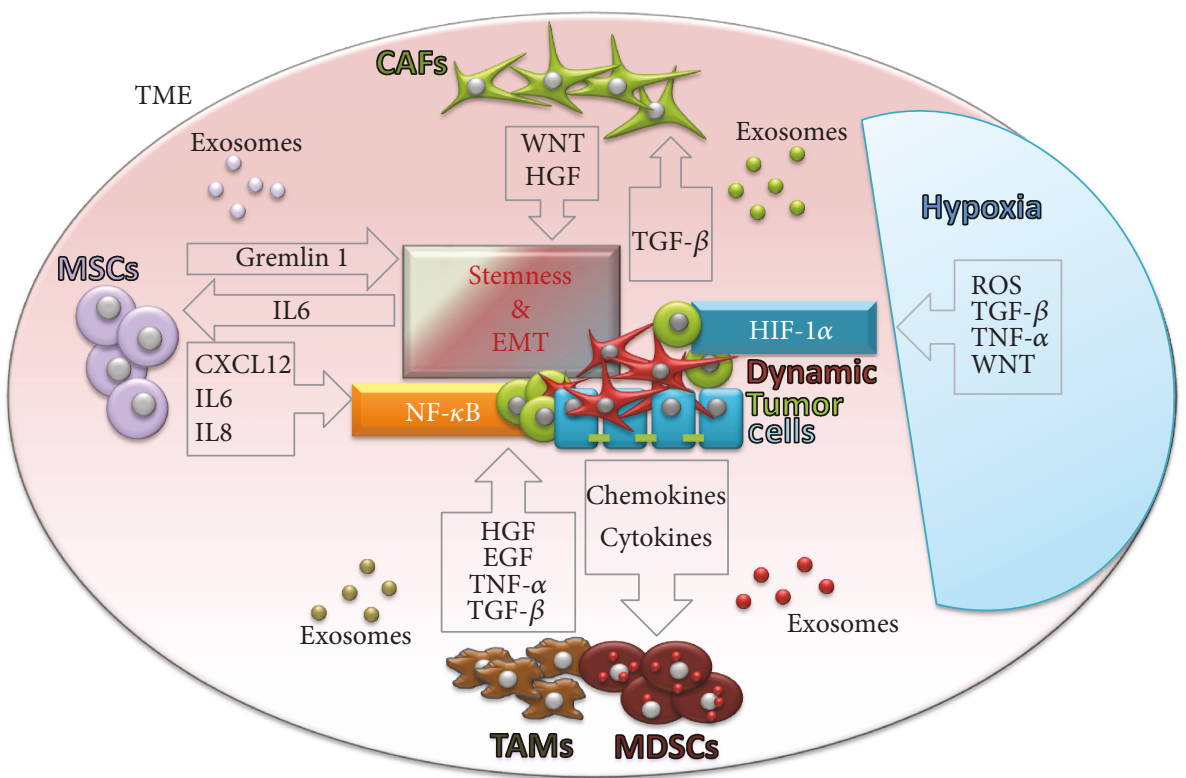

FIGURE 3: Tumor microenvironment and cancer cell phenotype. Schematic representation of TME influence on stemness and mesenchymal properties of cancer cells. The dynamic phenotype of cancer cells (stemness, EMT) is regulated by several signaling pathways. TGF- $\beta$ and NF$\kappa \mathrm{B}$ signaling pathways are activated by different microenvironmental factors like MSCs, CAFs, TAMs, MDSCs, or hypoxia. Exosomes derived from respective cell types play an important role in intercellular paracrine communication.

tumor. Although the importance of the differentiation state of tumor cells on their malignant capacity has been reported since the $80 \mathrm{~s}$, the study of the underlying mechanism controlling these cellular states has been neglected until recently [37]. Currently, the most studied phenomenon of cellular differentiation/dedifferentiation processes undergone by tumor cells with influence in cancer progression is transition from epithelial to mesenchymal phenotype and their counter pathway mesenchymal to epithelial transition. Both phenomena have been reported in several cancer types including colorectal cancer, breast cancer, prostate cancer, pancreatic cancer, bladder cancer, and lung cancer, among others. EMT cellular conversion has been extensively studied during the last decade. In this regard, three main molecular pathways leading and regulating this process have been proposed: (a) SMAD/TGF- $\beta$ pathway, (b) WNT/ $\beta$ catenin signaling, and (c) ECM integrin signaling cascade. In any case, these diverse EMT routes render upregulation of specific sets of transcription factors, including SNAIL, SLUG, ZEB, and TWIST, that would further control the cellular conversion process [20, 38, 39].

CSCs and non-CSC populations have also been proved able to interconvert each other depending on external stimuli, namely, factors coming from the microenvironment or in response to treatment. Some examples of differentiated cells undergoing this reversion process to become CSCs, or cells in an intermediate state showing stem-like properties, have been reported for colorectal cancer, breast cancer, and melanoma, among others $[17,40-42]$. Interestingly, two of the EMT pathways (SMAD/TGF- $\beta$ and WNT/ $\beta$-CATENIN) have been associated also with the acquisition of stem-like properties [13].
Moreover, another important common activator of CSC reversion and EMT is hypoxia (Figure 3). Hypoxia induces the overexpression of OCT4 that in turns triggers a molecular cascade leading to enrichment of cells with CSC-like phenotype in melanoma [43]. Hypoxic condition also induces the overexpression of hypoxia-inducible factors (HIFs), which can directly induce EMT in various cancer models, mostly conducted by the HIF- $1 \alpha$ factor (Figure 3) [44, 45]. Importantly, HIF- $1 \alpha$ can directly increase NOTCH signaling, enhancing stemness [46]. Hypoxia also promotes CSC survival and EMT through reactive oxygen species- (ROS-) activated stress response pathways and through ROSinduced TGF- $\beta$ and TNF- $\alpha$ signaling pathways, in breast cancer (Figure 3) [47]. In glioma cells, the activation of TGF- $\beta$ as well as WNT signaling pathways by hypoxia induces stemness by promoting an undifferentiated cellular state [48]. Furthermore, hypoxia seems sufficient to promote CSC phenotype and invasion and accelerate metastatic outgrowth in liver tumor cells after surgery. In addition, transcription factors recognized as pluripotency markers in embryonic stem cells such as NANOG, SOX2, and c-MYC have been reported to be upregulated in the acquirement of the CSC profile [49].

Despite some scraps of evidence from distinct tumor types showing the acquirement of stemness properties by differentiated cells in specific conditions, the general process by which differentiated tumor cells undergo a dedifferentiation process is still far from being completely elucidated. However, what seems clear is that the dynamism described for CSCs is analogous to the dynamism observed for EMT processes. Despite that signals and subsequent pathways triggering both processes are not necessarily shared, the 
acquisition of CSC phenotype and EMT partially overlaps, which goes in line with partial EMT phenotype and the CSC window theory discussed before (Figure 2). Nonetheless, the fact that signaling cascades for both processes differ by enhancing the expression of distinct subsets of transcription factors is remarkable. Therefore, although in some cases EMT and non-CSC to CSC reversion produce similar responses related with an increased malignancy of the disease, they should be considered distinct processes, both highly dependent on the cancer type.

\section{Tumor Microenvironment and Cancer Cell Phenotype}

Another important modulator of the phenotypic plasticity of cancer cells may come from the tumor microenvironment (TME), also called tumor niche (Figure 3). TME is composed of a complex network of stromal, immune, and inflammatory cells; soluble factors; signaling molecules; and the extracellular matrix [50]. Both cellular and noncellular components of the tumor niche contribute to maintaining the stemness of tumor cells and regulating EMT/MET and CSC plasticity $[45,51,52]$.

The most abundant cell population within TME are fibroblasts [53]. Solid evidences show that cancer cells are capable of producing factors, like TGF- $\beta$, that once secreted to the TME can transform normal fibroblasts into cancerassociated fibroblasts (CAFs) [54]. CAFs have a battery of unique features when compared with normal fibroblasts that promote cancer progression [55]. It has been demonstrated that TGF- $\beta$ is carried to the tumor stroma by cancer cells, enhancing CAF phenotype. Once activated, CAFs promote tumor cell progression by multiple mechanisms, in a bidirectional crosstalk between CAFs and tumor cells [56]. One of the most important players in cell-to-cell communication in the TME are exosomes [57]. Exosomes are specialized membranous nanosized vesicles $(30-150 \mathrm{~nm})$ derived from endocytic compartments that are released by many cell types. They contain sophisticated RNA and protein cargos from the cell of origin, enabling intercellular communication [58]. Exosomes released by activated CAFs have been associated with the promotion of EMT, stemness, and angiogenesis in prostate tumors [59-61]. Special relevance has been attributed to the WNT pathway, a crucial signaling cascade for these processes. The upregulation of WNT10b in CAF exosomes induces EMT of breast cancer cells [62]. A study with endometrial cancer cells has also demonstrated that upregulation of WNT10b in CAFs results in increased migration and aggressiveness of tumor cells [63]. Besides, in lung cancer models, CAFs obtained from lung cancer tissue produce hepatocyte growth factor (HGF), thereby activating the EMT-related c-Met pathway (Figure 3) [64].

Moreover, TME also contains mesenchymal stem cells (MSCs) that are considered key regulators of tumoral physiology through multiple mechanisms [65-67]. These multipotent stromal cells are implicated in the restoration of CSCs in the TME. Similar to CAFs, MSCs can promote cancer stemness and EMT phenotype also through TGF- $\beta$ [68] Moreover, MSCs can stimulate tumor progression by producing
Gremlin 1 to promote the undifferentiated state of cancer cells [69]. Furthermore, MSCs can provide tumor cells with CSCs properties by suppressing FOXP2 expression [70]. Exosomes released by MSC cells are important for communication of MSCs with TME, although further studies are needed to better elucidate completely their role (Figure 3 ). Another area of great interest is the influence of the TME in modulating tumoral immunity [68]. Accumulating data is pointing out that tumor-polarized immune cells resident in the TME enhance EMT phenotype and ultimately promote migration and invasion of CSCs [71].

The TME is characterized by chronic inflammation which leads to a phenomenon called immunosuppression in the tumor niche that stimulates tumor cell proliferation and metastasis. Tumor-associated macrophages (TAMs) and myeloid-derived suppressor cells (MDSCs) are an example of immunosuppressive cell types recruited by chemokines and cytokines that are secreted by cancer cells. TAMs are derived from polarized macrophages that acquire protumor phenotypes that enhance tumor growth and metastasis [72]. Similarly to previous examples, tumor-derived exosomes have been shown to play a key role in macrophage polarization. Within inflammatory TME, TAMs and $\mathrm{CD} 4^{+}$ T cells secrete TNF- $\alpha$ which upregulates NF- $\kappa$ B signaling, induce EMT, and increase the crosstalk with the TGF- $\beta$ signaling pathway, stimulating stemness [71]. In agreement to this, gastric cancer-derived exosomes have been shown to induce NF- $\kappa \mathrm{B}$ activation in macrophages promoting the proliferation of gastric cancer cells. Similar results show that breast cancer-derived exosomes also stimulate the NF- $\kappa \mathrm{B}$ pathway in macrophages [73]. On the other hand, MDSCs are a heterogeneous population of cells from monocytic and granulocytic origins, which are also involved in promoting EMT and in CSC maintenance [74]. Indeed, in a spontaneous murine model of melanoma, MDSCs induce EMT via TGF- $\beta$, EGF, and HGF signaling [75]. Similarly, platelet-derived TGF- $\beta$ secreted by MDSCs activates TGF$\beta /$ Smad and NF- $\kappa$ B pathways in lung cancer cells, resulting in EMT and enhanced metastasis in vivo, in lung cancer models $[76,77]$.

\section{Implication of Cancer Cell Phenotypes in Anti-Tumoral Treatment Strategies}

Understanding the tight relationship among CSCs, EMT, and the tumoral microenvironment opens the door to new strategies for developing more effective anticancer treatments.

Because many CSC-related pathways are involved also in EMT, new treatments should eliminate CSCs while reverting the EMT phenotype and vice versa. For example, in order to target EMT, different strategies have been reported, usually targeting (i) adhesion-related proteins (e.g., E-cadherin), (ii) microenvironment factors (e.g., SPARC), (iii) cell membrane molecules (e.g., integrins, TGF- $\beta$ ), (iv) intracellular transcription factors (e.g., ZEB, SNAIL, SLUG, TWIST, and E47), (v) microRNAs (e.g., miRNA200, miRNA29), and a wide range of other possibilities [78]. On the other hand, the elimination of CSCs is pursued through different 


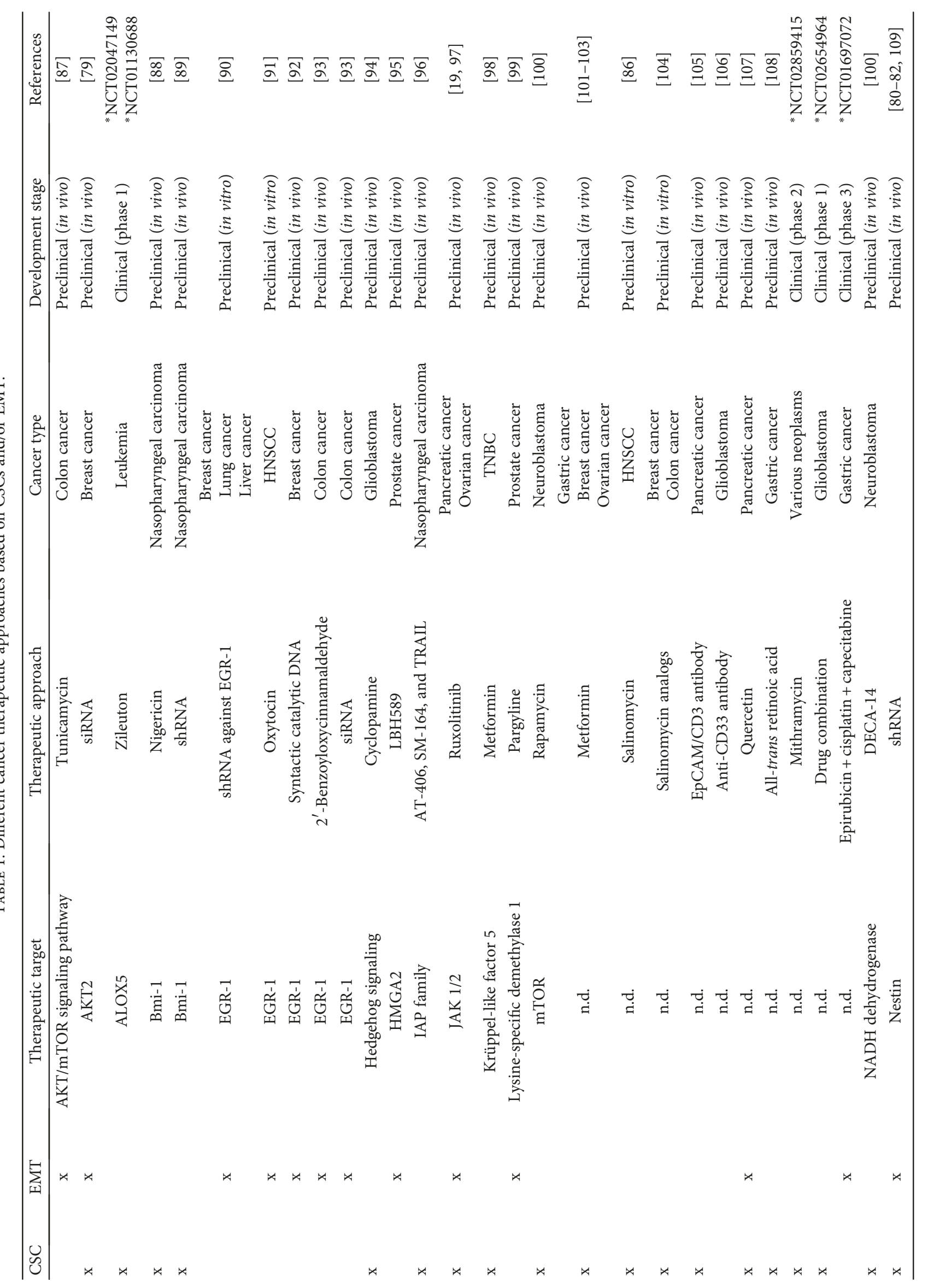




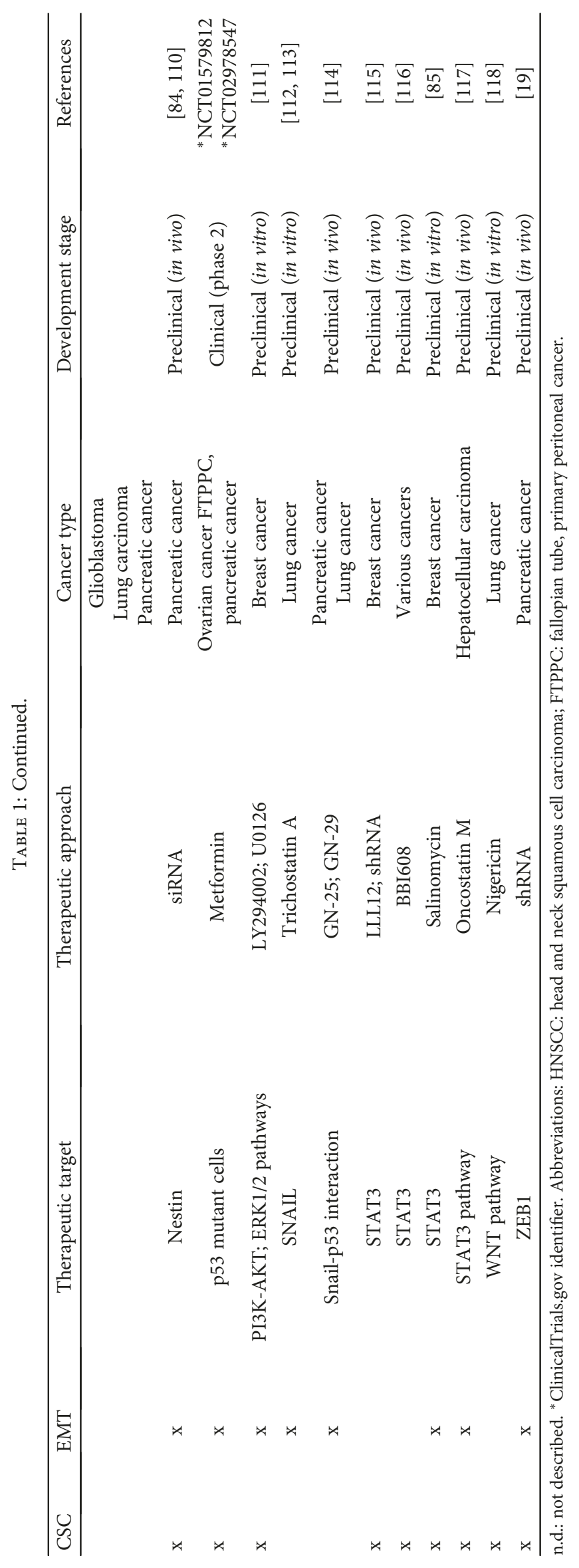


therapeutic strategies involving signaling pathways related with (i) CSC survival and proliferation pathways (e.g., PI3K-AKT, JAK/STAT, and NF- $\kappa \mathrm{B}$ ) and (ii) signals linked to the stemness properties of CSCs, like self-renewal and pluripotency (e.g., Notch pathway, WNT pathway, and Hedgehog signaling) [5]. However, the molecular pathways studied as potential EMT targets are also involved in CSCs stemness, and the ones studied as CSC pathways are usually representative of EMT. Studies characterizing the effect of specific molecular players on the regulation of both CSC malignancy and EMT occurrence are still scarce. As an example, the PI3K-AKT pathway regulates the expression of TWIST, one of the most important transcription factors regulating EMT; however, the same pathway is also reported as crucial for stemness properties and CSCs survival [79].

As referred, CSCs and EMT cells partially share signaling pathways of EMT and stemness and since CSCs could undergo EMT, it is virtually impossible to characterize a therapeutic target or approach as CSC- or EMT-specific. Moreover, many studies regarding treatments directed against CSCs do not assess the therapeutic effect on EMT and vice versa, making more difficult to comprehend the interactive effects between both phenomena.

An example is Nestin, a class VI intermediate filament protein involved in mitosis. It was originally described as a neural stem cell/progenitor cell marker. However, expression of Nestin has been reported to be associated with migration and metastasis of various types of tumors and as a CSC marker [80-83]. Transfection of the tumor cancer cell line PANC-1 with a short hairpin RNA (shRNA) targeting NESTIN results in decreased NESTIN expression, increased expression of filamentous $\mathrm{F}$-actin and E-cadherin, reduction of cell migration and invasion abilities, and less formation of metastasis in vivo, demonstrating its involvement in EMT [80]. Additionally, NESTIN and CSC markers like ALDH1A1 and ABCG2 are found overexpressed in metastasis-derived cancer cells presenting low levels of Ecadherin. NESTIN silencing in pancreatic cancer results in reduced sphere formation, tumor growth, and metastasis development, not only suggesting the correlation between the CSC-like phenotype and EMT but also validating NESTIN as a therapeutic target [84].

The effects of a drug in CSCs and also in the EMT process are dependent on the cell and cancer type. In triple-negative breast cancer (TNBC), salinomycin was described to cause marked suppression of cell migration and invasion as well as inhibition of mammosphere formation and effective reduction of the $\mathrm{CD} 44^{+} / \mathrm{CD} 24^{-}$stem-like/mesenchymal subpopulation [85]. On the other hand, in case of head and neck squamous cell carcinoma, salinomycin treatment induces apoptosis and decrease in stem cell properties, despite the activation of EMT via AKT [86]. These observed differences between studies and cancer type could be explained by the previously referred stemness window theory (Figure 2).

The best strategy to prevent tumor remission should be the elimination of all kinds of aggressive cells within the tumor together with the bulk tumor cells since these cells have interconversion capacity and could originate new clones of CSCs or mesenchymal cell via the EMT process. Therefore, the ultimate goal for the cancer treatment field is to find the way to reach all types of cancer cells. This could be achieved by treatment protocols implying combination of various therapeutic molecules, a combination of gene therapy approaches, or the use of targeted vectors decorated with the most specific ligands found for each type of cell.

Nowadays, different therapeutic approaches have been proposed to target CSCs and/or EMT, ongoing different development stages (Table 1). Since this therapeutic approach is still in its infancy, the majority of present studies are at the preclinical phase, with a small percentage enrolling clinical evaluation. More examples of treatments under clinical trials against CSCs and/or EMT can be found at [5].

\section{Summary}

The stemness of CSCs, non-CSC reversion to CSCs, and EMT processes are regulated by similar signaling pathways. Provided data show that when TGF- $\beta$ and NF- $\kappa \beta$ signaling cascade is activated by different microenvironmental factors, cancer cells from various cancer types tend to undergo EMT, and this is frequently accompanied by a maintenance of a CSC stem phenotype. Based on this knowledge, strategies to prevent tumor remission should carefully consider not only eliminating potential aggressive CSCs and EMT cells within the tumor but also targeting those signaling pathways responsible for the interconversion capacity of non-CSCs to new CSCs and mesenchymal cells via EMT activation. This can be undergone through a combination of molecules, a combination of gene therapy approaches, or the use of targeted vectors decorated with the most specific ligands found for each cell type.

\section{Abbreviations}

TME: Tumor microenvironment

CAFs: Cancer-associated fibroblasts

MSCs: Mesenchymal stem cells

TAMs: Tumor-associated macrophages

MDSCs: Myeloid-derived suppressor cells.

\section{Conflicts of Interest}

No potential conflict of interest was reported by the authors.

\section{Acknowledgments}

This work was partially supported by grants PI14/02079 and PI17/02242 from Fondo de Investigaciones Sanitarias (FIS) of Instituto Carlos III (ISCIII), cofinanced by the European Regional Development Fund (FEDER), and grant AC15/ 00092 (Target4Cancer project) from EuroNanoMed II to SS and grant 337/C/2013 (PENTRI project) from Fundació Marató TV3 (Catalonia, Spain) to IA. The Portuguese Science and Technology Foundation (FCT) supported FA with a postdoctoral grant (SFRH/BD/76270/2011). La Asociación Española Contra el Cáncer (AECC) supported 
JSF with a postdoctoral fellowship. Plan Estratégico de Investigación e Innovación en Salud (PERIS) supported FM.

\section{References}

[1] N. McGranahan and C. Swanton, "Clonal heterogeneity and tumor evolution: past, present, and the future," Cell, vol. 168, no. 4, pp. 613-628, 2017.

[2] K. Dzobo, D. A. Senthebane, A. Rowe et al., "Cancer stem cell hypothesis for therapeutic innovation in clinical oncology? Taking the root out, not chopping the leaf," OMICS: A Journal of Integrative Biology, vol. 20, no. 12, pp. 681-691, 2016.

[3] K. Eun, S. W. Ham, and H. Kim, "Cancer stem cell heterogeneity: origin and new perspectives on CSC targeting," BMB Reports, vol. 50, no. 3, pp. 117-125-125, 2017.

[4] A. Mitra, L. Mishra, and S. Li, "EMT, CTCs and CSCs in tumor relapse and drug-resistance," Oncotarget, vol. 6, no. 13, pp. 10697-10711, 2015.

[5] P. Gener, D. F. d. S. Rafael, Y. Fernández et al., "Cancer stem cells and personalized cancer nanomedicine," Nanomedicine, vol. 11, no. 3, pp. 307-320, 2016.

[6] P. Gener, L. P. Gouveia, G. R. Sabat et al., "Fluorescent CSC models evidence that targeted nanomedicines improve treatment sensitivity of breast and colon cancer stem cells," Nanomedicine: Nanotechnology, Biology and Medicine, vol. 11, no. 8, pp. 1883-1892, 2015.

[7] M. Zeisberg and E. G. Neilson, "Biomarkers for epithelialmesenchymal transitions," The Journal of Clinical Investigation, vol. 119, no. 6, pp. 1429-1437, 2009.

[8] J. A. Davies and D. R. Garrod, "Molecular aspects of the epithelial phenotype," BioEssays, vol. 19, no. 8, pp. 699-704, 1997.

[9] A. P. Sappino, W. Schürch, and G. Gabbiani, "Differentiation repertoire of fibroblastic cells: expression of cytoskeletal proteins as marker of phenotypic modulations," Laboratory Investigation, vol. 63, no. 2, pp. 144-161, 1990.

[10] R. Moll, W. W. Franke, D. L. Schiller, B. Geiger, and R. Krepler, "The catalog of human cytokeratins: patterns of expression in normal epithelia, tumors and cultured cells," Cell, vol. 31, no. 1, pp. 11-24, 1982.

[11] D. Cooper, A. Schermer, and T. T. Sun, "Classification of human epithelia and their neoplasms using monoclonal antibodies to keratins: strategies, applications, and limitations," Laboratory Investigation, vol. 52, no. 3, pp. 243-256, 1985.

[12] D. Sarrio, C. K. Franklin, A. Mackay, J. S. Reis-Filho, and C. M. Isacke, "Epithelial and mesenchymal subpopulations within normal basal breast cell lines exhibit distinct stem cell/progenitor properties," Stem Cells, vol. 30, no. 2, pp. 292-303, 2012.

[13] S. A. Mani, W. Guo, M. J. Liao et al., "The epithelialmesenchymal transition generates cells with properties of stem cells," Cell, vol. 133, no. 4, pp. 704-715, 2008.

[14] M. K. Jolly, M. Boareto, B. Huang et al., "Implications of the hybrid epithelial/mesenchymal phenotype in metastasis," Frontiers in Oncology, vol. 5, p. 155, 2015.

[15] C. Scheel and R. A. Weinberg, "Cancer stem cells and epithelial-mesenchymal transition: concepts and molecular links," Seminars in Cancer Biology, vol. 22, no. 5-6, pp. 396-403, 2012.

[16] Z. Yi, D. Yang, X. Liao, F. Guo, Y. Wang, and X. Wang, "PSME3 induces epithelial-mesenchymal transition with inducing the expression of CSC markers and immunosuppression in breast cancer," Experimental Cell Research, vol. 358, no. 2, pp. 87-93, 2017.

[17] U. Wellner, J. Schubert, U. C. Burk et al., “The EMT-activator ZEB1 promotes tumorigenicity by repressing stemnessinhibiting microRNAs," Nature Cell Biology, vol. 11, no. 12, pp. 1487-1495, 2009.

[18] R. Strauss, Z.-Y. Li, Y. Liu et al., "Analysis of epithelial and mesenchymal markers in ovarian cancer reveals phenotypic heterogeneity and plasticity," PLoS One, vol. 6, article e16186, no. 1, 2011.

[19] J. M. Smigiel, N. Parameswaran, and M. W. Jackson, "Potent EMT and CSC phenotypes are induced by oncostatin-M in pancreatic cancer," Molecular Cancer Research, vol. 15, no. 4, pp. 478-488, 2017.

[20] T. Shibue and R. A. Weinberg, "EMT, CSCs, and drug resistance: the mechanistic link and clinical implications," Nature Reviews Clinical Oncology, vol. 14, no. 10, pp. 611-629, 2017.

[21] T. Z. Tan, Q. H. Miow, Y. Miki et al., "Epithelial-mesenchymal transition spectrum quantification and its efficacy in deciphering survival and drug responses of cancer patients," EMBO Molecular Medicine, vol. 6, no. 10, pp. 1279-1293, 2014.

[22] A. Grosse-Wilde, A. Fouquier d'Hérouël, E. McIntosh et al., "Stemness of the hybrid epithelial/mesenchymal state in breast cancer and its association with poor survival," PLoS One, vol. 10, no. 5, article e0126522, 2015.

[23] M. Ruscetti, B. Quach, E. L. Dadashian, D. J. Mulholland, and $\mathrm{H}$. Wu, "Tracking and functional characterization of epithelial-mesenchymal transition and mesenchymal tumor cells during prostate cancer metastasis," Cancer Research, vol. 75, no. 13, pp. 2749-2759, 2015.

[24] O. H. Ocaña, R. Córcoles, Á. Fabra et al., "Metastatic colonization requires the repression of the epithelial-mesenchymal transition inducer Prrx1," Cancer Cell, vol. 22, no. 6, pp. 709-724, 2012.

[25] T. Celià-Terrassa, Ó. Meca-Cortés, F. Mateo et al., "Epithelial-mesenchymal transition can suppress major attributes of human epithelial tumor-initiating cells," The Journal of Clinical Investigation, vol. 122, no. 5, pp. 18491868, 2012.

[26] J. H. Tsai, J. L. Donaher, D. A. Murphy, S. Chau, and J. Yang, "Spatiotemporal regulation of epithelial-mesenchymal transition is essential for squamous cell carcinoma metastasis," Cancer Cell, vol. 22, no. 6, pp. 725-736, 2012.

[27] T. Tsuji, S. Ibaragi, K. Shima et al., "Epithelial-mesenchymal transition induced by growth suppressor $\mathrm{p} 12^{\mathrm{CDK} 2-\mathrm{AP} 1}$ promotes tumor cell local invasion but suppresses distant colony growth," Cancer Research, vol. 68, no. 24, pp. 10377-10386, 2008.

[28] P. Samavarchi-Tehrani, A. Golipour, L. David et al., "Functional genomics reveals a BMP-driven mesenchymal-toepithelial transition in the initiation of somatic cell reprogramming," Cell Stem Cell, vol. 7, no. 1, pp. 64-77, 2010.

[29] R. Li, J. Liang, S. Ni et al., "A mesenchymal-to-epithelial transition initiates and is required for the nuclear reprogramming of mouse fibroblasts," Cell Stem Cell, vol. 7, no. 1, pp. 51-63, 2010.

[30] M. K. Jolly, B. Huang, M. Lu, S. A. Mani, H. Levine, and E. Ben-Jacob, "Towards elucidating the connection between epithelial-mesenchymal transitions and stemness," Journal 
of The Royal Society Interface, vol. 11, no. 101, p. 20140962, 2014.

[31] A. J. Armstrong, M. S. Marengo, S. Oltean et al., "Circulating tumor cells from patients with advanced prostate and breast cancer display both epithelial and mesenchymal markers," Molecular Cancer Research, vol. 9, no. 8, pp. 997-1007, 2011.

[32] C. Alix-Panabières and K. Pantel, "Challenges in circulating tumour cell research," Nature Reviews Cancer, vol. 14, no. 9, pp. 623-631, 2014.

[33] W. L. Tam and R. A. Weinberg, "The epigenetics of epithelial-mesenchymal plasticity in cancer," Nature Medicine, vol. 19, no. 11, pp. 1438-1449, 2013.

[34] M. I. Yovchev, P. N. Grozdanov, H. Zhou, H. Racherla, C. Guha, and M. D. Dabeva, "Identification of adult hepatic progenitor cells capable of repopulating injured rat liver," Hepatology, vol. 47, no. 2, pp. 636-647, 2008.

[35] A. Conigliaro, L. Amicone, V. Costa et al., "Evidence for a common progenitor of epithelial and mesenchymal components of the liver," Cell Death \& Differentiation, vol. 20, no. 8, pp. 1116-1123, 2013.

[36] C. Cicchini, L. Amicone, T. Alonzi, A. Marchetti, C. Mancone, and M. Tripodi, "Molecular mechanisms controlling the phenotype and the EMT/MET dynamics of hepatocyte," Liver International, vol. 35, no. 2, pp. 302-310, 2015.

[37] H. Gabbert, R. Wagner, R. Moll, and C.-D. Gerharz, “Tumor dedifferentiation: an important step in tumor invasion," Clinical \& Experimental Metastasis, vol. 3, no. 4, pp. 257279, 1985.

[38] J. Xu, S. Lamouille, and R. Derynck, “TGF- $\beta$-induced epithelial to mesenchymal transition," Cell Research, vol. 19, no. 2, pp. 156-172, 2009.

[39] J. Zavadil and E. P. Böttinger, "TGF- $\beta$ and epithelial-tomesenchymal transitions," Oncogene, vol. 24, no. 37, pp. 5764-5774, 2005.

[40] S. M. Kumar, S. Liu, H. Lu et al., "Acquired cancer stem cell phenotypes through Oct4-mediated dedifferentiation," Oncogene, vol. 31, no. 47, pp. 4898-4911, 2012.

[41] C. L. Chaffer, I. Brueckmann, C. Scheel et al., "Normal and neoplastic nonstem cells can spontaneously convert to a stem-like state," Proceedings of the National Academy of Sciences of the United States of America, vol. 108, no. 19, pp. 7950-7955, 2011.

[42] D. Klevebring, G. Rosin, R. Ma et al., "Sequencing of breast cancer stem cell populations indicates a dynamic conversion between differentiation states in vivo," Breast Cancer Research, vol. 16, no. 4, p. R72, 2014.

[43] Y.-J. Wang and M. Herlyn, "The emerging roles of Oct4 in tumor-initiating cells," American Journal of Physiology-Cell Physiology, vol. 309, no. 11, pp. C709-C718, 2015.

[44] D. M. Gilkes and G. L. Semenza, "Role of hypoxia-inducible factors in breast cancer metastasis," Future Oncology, vol. 9, no. 11, pp. 1623-1636, 2013.

[45] V. Plaks, N. Kong, and Z. Werb, "The cancer stem cell niche: how essential is the niche in regulating stemness of tumor cells?," Cell Stem Cell, vol. 16, no. 3, pp. 225-238, 2015.

[46] H. Moriyama, M. Moriyama, T. Ozawa et al., "Notch signaling enhances stemness by regulating metabolic pathways through modifying p53, NF- $\kappa \mathrm{B}$, and HIF- $1 \alpha$, Stem Cells and Development, vol. 27, no. 13, pp. 935-947, 2018.
[47] S. Pavlides, A. Tsirigos, I. Vera et al., "Transcriptional evidence for the "reverse Warburg effect" in human breast cancer tumor stroma and metastasis: similarities with oxidative stress, inflammation, Alzheimer's disease, and "neuron-glia metabolic coupling"," Aging, vol. 2, no. 4, pp. 185-199, 2010.

[48] J. Anido, A. Sáez-Borderías, A. Gonzàlez-Juncà et al., “TGF- $\beta$ receptor inhibitors target the CD $44^{\text {high }} / \mathrm{Id} 1^{\text {high }}$ gliomainitiating cell population in human glioblastoma," Cancer Cell, vol. 18, no. 6, pp. 655-668, 2010.

[49] Y. Li and J. Laterra, "Cancer stem cells: distinct entities or dynamically regulated phenotypes?," Cancer Research, vol. 72, no. 3, pp. 576-580, 2012.

[50] M. Wang, J. Zhao, L. Zhang et al., "Role of tumor microenvironment in tumorigenesis," Journal of Cancer, vol. 8, no. 5, pp. 761-773, 2017.

[51] M. Varas-Godoy, G. Rice, and S. E. Illanes, "The crosstalk between ovarian cancer stem cell niche and the tumor microenvironment," Stem Cells International, vol. 2017, Article ID 5263974, 8 pages, 2017.

[52] G. Lee and R. R. Hall, "Cancer stem cells: cellular plasticity, niche, and its clinical relevance," Journal of Stem Cell Research \& Therapy, vol. 6, no. 10, 2016.

[53] A. Orimo, P. B. Gupta, D. C. Sgroi et al., "Stromal fibroblasts present in invasive human breast carcinomas promote tumor growth and angiogenesis through elevated SDF-1/CXCL12 secretion," Cell, vol. 121, no. 3, pp. 335-348, 2005.

[54] R. Kalluri and M. Zeisberg, "Fibroblasts in cancer," Nature Reviews Cancer, vol. 6, no. 5, pp. 392-401, 2006.

[55] M. R. Junttila and F. J. de Sauvage, "Influence of tumour micro-environment heterogeneity on therapeutic response," Nature, vol. 501, no. 7467, pp. 346-354, 2013.

[56] J. Webber, R. Steadman, M. D. Mason, Z. Tabi, and A. Clayton, "Cancer exosomes trigger fibroblast to myofibroblast differentiation," Cancer Research, vol. 70, no. 23, pp. 9621-9630, 2010.

[57] J. Maia, S. Caja, M. C. Strano Moraes, N. Couto, and B. Costa-Silva, "Exosome-based cell-cell communication in the tumor microenvironment," Frontiers in Cell and Development Biology, vol. 6, p. 18, 2018.

[58] M. H. Rashed, E. Bayraktar, G. K. Helal et al., "Exosomes: from garbage bins to promising therapeutic targets," International Journal of Molecular Sciences, vol. 18, no. 3, p. 538, 2017.

[59] E. Giannoni, F. Bianchini, L. Masieri et al., "Reciprocal activation of prostate cancer cells and cancer-associated fibroblasts stimulates epithelial-mesenchymal transition and cancer stemness," Cancer Research, vol. 70, no. 17, pp. 6945-6956, 2010.

[60] T. Fiaschi, E. Giannoni, L. Taddei et al., "Carbonic anhydrase IX from cancer-associated fibroblasts drives epithelialmesenchymal transition in prostate carcinoma cells," Cell Cycle, vol. 12, no. 11, pp. 1791-1801, 2013.

[61] A. Ramteke, H. Ting, C. Agarwal et al., "Exosomes secreted under hypoxia enhance invasiveness and stemness of prostate cancer cells by targeting adherens junction molecules," Molecular Carcinogenesis, vol. 54, no. 7, pp. 554-565, 2015.

[62] Y. Chen, C. Zeng, Y. Zhan, H. Wang, X. Jiang, and W. Li, "Aberrant low expression of $\mathrm{p} 85 \alpha$ in stromal fibroblasts promotes breast cancer cell metastasis through exosomemediated paracrine wnt10b," Oncogene, vol. 36, no. 33, pp. 4692-4705, 2017. 
[63] K. S. Subramaniam, I. S. Omar, S. C. Kwong et al., "Cancerassociated fibroblasts promote endometrial cancer growth via activation of interleukin-6/STAT-3/c-Myc pathway," American Journal of Cancer Research, vol. 6, no. 2, pp. 200213, 2016.

[64] W. Wang, Q. Li, T. Yamada et al., "Crosstalk to stromal fibroblasts induces resistance of lung cancer to epidermal growth factor receptor tyrosine kinase inhibitors," Clinical Cancer Research, vol. 15, no. 21, pp. 6630-6638, 2009.

[65] B. G. Cuiffo and A. E. Karnoub, "Mesenchymal stem cells in tumor development: emerging roles and concepts," Cell Adhesion \& Migration, vol. 6, no. 3, pp. 220-230, 2012.

[66] T. Zhang, Y. Lee, Y. Rui, T. Cheng, X. Jiang, and G. Li, "Bone marrow-derived mesenchymal stem cells promote growth and angiogenesis of breast and prostate tumors," Stem Cell Research \& Therapy, vol. 4, no. 3, p. 70, 2013.

[67] K. Nishimura, S. Semba, K. Aoyagi, H. Sasaki, and H. Yokozaki, "Mesenchymal stem cells provide an advantageous tumor microenvironment for the restoration of cancer stem cells," Pathobiology, vol. 79, no. 6, pp. 290-306, 2012.

[68] S. M. Cabarcas, L. A. Mathews, and W. L. Farrar, "The cancer stem cell niche-there goes the neighborhood?," International Journal of Cancer, vol. 129, no. 10, pp. 2315-2327, 2011.

[69] H. Davis, S. Irshad, M. Bansal et al., "Aberrant epithelial GREM1 expression initiates colonic tumorigenesis from cells outside the stem cell niche," Nature Medicine, vol. 21, no. 1, pp. 62-70, 2015.

[70] B. G. Cuiffo, A. Campagne, G. W. Bell et al., "MSC-regulated microRNAs converge on the transcription factor FOXP2 and promote breast cancer metastasis," Cell Stem Cell, vol. 15, no. 6, pp. 762-774, 2014.

[71] A. L. Smith, T. P. Robin, and H. L. Ford, "Molecular pathways: targeting the TGF- $\beta$ pathway for cancer therapy," Clinical Cancer Research, vol. 18, no. 17, pp. 4514-4521, 2012.

[72] T. Chanmee, P. Ontong, K. Konno, and N. Itano, “Tumorassociated macrophages as major players in the tumor microenvironment," Cancers, vol. 6, no. 3, pp. 1670-1690, 2014.

[73] A. Chow, W. Zhou, L. Liu et al., "Macrophage immunomodulation by breast cancer-derived exosomes requires tolllike receptor 2-mediated activation of NF- $\kappa \mathrm{B}$," Scientific Reports, vol. 4, no. 1, p. 5750, 2014.

[74] C. Melzer, J. von der Ohe, and R. Hass, "Concise review: crosstalk of mesenchymal stroma/stem-like cells with cancer cells provides therapeutic potential," Stem Cells, vol. 36, no. 7, pp. 951-968, 2018.

[75] B. Toh, X. Wang, J. Keeble et al., "Mesenchymal transition and dissemination of cancer cells is driven by myeloidderived suppressor cells infiltrating the primary tumor," PLoS Biology, vol. 9, no. 9, article e1001162, 2011.

[76] M. Labelle, S. Begum, and R. O. Hynes, "Direct signaling between platelets and cancer cells induces an epithelialmesenchymal-like transition and promotes metastasis," Cancer Cell, vol. 20, no. 5, pp. 576-590, 2011.

[77] R. S. Lindoso, F. Collino, and A. Vieyra, "Extracellular vesicles as regulators of tumor fate: crosstalk among cancer stem cells, tumor cells and mesenchymal stem cells," Stem Cell Investigation, vol. 4, no. 9, p. 75, 2017.

[78] D. Rafael, S. Doktorovova, H. F. Florindo et al., "EMT blockage strategies: targeting Akt dependent mechanisms for breast cancer metastatic behaviour modulation," Current Gene Therapy, vol. 15, no. 3, pp. 300-312, 2015.

[79] D. Rafael, P. Gener, F. Andrade et al., "AKT2 siRNA delivery with amphiphilic-based polymeric micelles show efficacy against cancer stem cells," Drug Delivery, vol. 25, no. 1, pp. 961-972, 2018.

[80] Y. Matsuda, Z. Naito, K. Kawahara, N. Nakazawa, M. Korc, and T. Ishiwata, "Nestin is a novel target for suppressing pancreatic cancer cell migration, invasion and metastasis," Cancer Biology \& Therapy, vol. 11, no. 5, pp. 512-523, 2011.

[81] Y. Matsuda, T. Ishiwata, H. Yoshimura, M. Hagio, and T. Arai, "Inhibition of nestin suppresses stem cell phenotype of glioblastomas through the alteration of post-translational modification of heat shock protein HSPA8/HSC71," Cancer Letters, vol. 357, no. 2, pp. 602-611, 2015.

[82] K. Narita, Y. Matsuda, M. Seike, Z. Naito, A. Gemma, and T. Ishiwata, "Nestin regulates proliferation, migration, invasion and stemness of lung adenocarcinoma," International Journal of Oncology, vol. 44, no. 4, pp. 1118-1130, 2014.

[83] M. Akiyama, Y. Matsuda, T. Ishiwata, Z. Naito, and S. Kawana, "Inhibition of the stem cell marker nestin reduces tumor growth and invasion of malignant melanoma," Journal of Investigative Dermatology, vol. 133, no. 5, pp. 1384-1387, 2013.

[84] Y. Matsuda, T. Ishiwata, H. Yoshimura, S. Yamashita, T. Ushijima, and T. Arai, "Systemic administration of small interfering RNA targeting human nestin inhibits pancreatic cancer cell proliferation and metastasis," Pancreas, vol. 45, no. 1, pp. 93-100, 2016.

[85] H. An, J. Y. Kim, E. Oh, N. Lee, Y. Cho, and J. H. Seo, "Salinomycin promotes anoikis and decreases the $\mathrm{CD} 44^{+} / \mathrm{CD} 24^{-}$ stem-like population via inhibition of STAT3 activation in MDA-MB-231 cells," PLoS One, vol. 10, no. 11, article e0141919, 2015.

[86] S. Z. Kuo, K. J. Blair, E. Rahimy et al., "Salinomycin induces cell death and differentiation in head and neck squamous cell carcinoma stem cells despite activation of epithelialmesenchymal transition and Akt," BMC Cancer, vol. 12, no. 1, 2012.

[87] S. You, W. Li, and Y. Guan, "Tunicamycin inhibits colon carcinoma growth and aggressiveness via modulation of the ERK-JNK-mediated Akt/mTOR signaling pathway," Molecular Medicine Reports, vol. 17, no. 3, pp. 4203-4212, 2018.

[88] C.-C. Deng, Y. Liang, M.-S. Wu et al., "Nigericin selectively targets cancer stem cells in nasopharyngeal carcinoma," The International Journal of Biochemistry \& Cell Biology, vol. 45, no. 9, pp. 1997-2006, 2013.

[89] X. Xu, Y. Liu, J. Su et al., "Downregulation of Bmi-1 is associated with suppressed tumorigenesis and induced apoptosis in CD44+ nasopharyngeal carcinoma cancer stem-like cells," Oncology Reports, vol. 35, no. 2, pp. 923-931, 2016.

[90] H. M. Jeon, S. Y. Lee, M. K. Ju, C. H. Kim, H. G. Park, and H. S. Kang, "Early growth response 1 regulates glucose deprivation-induced necrosis," Oncology Reports, vol. 29, no. 2, pp. 669-675, 2013.

[91] J. Kim, S.-M. Kang, H.-J. Lee, S.-Y. Choi, and S.-H. Hong, "Oxytocin inhibits head and neck squamous cell carcinoma cell migration by early growth response-1 upregulation," Anti-Cancer Drugs, vol. 28, no. 6, pp. 613-622, 2017.

[92] A. Mitchell, C. R. Dass, L. Q. Sun, and L. M. Khachigian, "Inhibition of human breast carcinoma proliferation, 
migration, chemoinvasion and solid tumour growth by DNAzymes targeting the zinc finger transcription factor EGR-1," Nucleic Acids Research, vol. 32, no. 10, pp. 30653069, 2004.

[93] J. Kim, H. S. Kang, Y.-J. Lee et al., "EGR1-dependent PTEN upregulation by 2-benzoyloxycinnamaldehyde attenuates cell invasion and EMT in colon cancer," Cancer Letters, vol. 349, no. 1, pp. 35-44, 2014.

[94] E. E. Bar, A. Chaudhry, A. Lin et al., "Cyclopamine-mediated hedgehog pathway inhibition depletes stem-like cancer cells in glioblastoma," Stem Cells, vol. 25, no. 10, pp. 2524-2533, 2007.

[95] M. Ruscetti, E. L. Dadashian, W. Guo et al., "HDAC inhibition impedes epithelial-mesenchymal plasticity and suppresses metastatic, castration-resistant prostate cancer," Oncogene, vol. 35, no. 29, pp. 3781-3795, 2016.

[96] M. S. Wu, G. F. Wang, Z. Q. Zhao et al., "Smac mimetics in combination with TRAIL selectively target cancer stem cells in nasopharyngeal carcinoma," Molecular Cancer Therapeutics, vol. 12, no. 9, pp. 1728-1737, 2013.

[97] P. M. Reeves, M. A. Abbaslou, F. R. W. Kools et al., "Ruxolitinib sensitizes ovarian cancer to reduced dose taxol, limits tumor growth and improves survival in immune competent mice," Oncotarget, vol. 8, no. 55, pp. 9404094053, 2017.

[98] P. Shi, W. Liu, Tala et al., "Metformin suppresses triplenegative breast cancer stem cells by targeting KLF5 for degradation," Cell Discovery, vol. 3, article 17010, 2017.

[99] M. Wang, X. Liu, J. Guo et al., "Inhibition of LSD1 by pargyline inhibited process of EMT and delayed progression of prostate cancer in vivo," Biochemical and Biophysical Research Communications, vol. 467, no. 2, pp. 310-315, 2015.

[100] K. M. Smith, A. Datti, M. Fujitani et al., "Selective targeting of neuroblastoma tumour-initiating cells by compounds identified in stem cell-based small molecule screens," $E M B O$ Molecular Medicine, vol. 2, no. 9, pp. 371-384, 2010.

[101] S. Courtois, R. V. Durán, J. Giraud et al., "Metformin targets gastric cancer stem cells," European Journal of Cancer, vol. 84, pp. 193-201, 2017.

[102] H. A. Hirsch, D. Iliopoulos, and K. Struhl, "Metformin inhibits the inflammatory response associated with cellular transformation and cancer stem cell growth," Proceedings of the National Academy of Sciences of the United States of America, vol. 110, no. 3, pp. 972-977, 2013.

[103] J. J. Shank, K. Yang, J. Ghannam et al., "Metformin targets ovarian cancer stem cells in vitro and in vivo," Gynecologic Oncology, vol. 127, no. 2, pp. 390-397, 2012.

[104] X. Huang, B. Borgström, S. Kempengren et al., "Breast cancer stem cell selectivity of synthetic nanomolar-active salinomycin analogs," BMC Cancer, vol. 16, no. 1, p. 145, 2016.

[105] A. V. Salnikov, A. Groth, A. Apel et al., "Targeting of cancer stem cell marker epCAM by bispecific antibody EpCAMxCD3 inhibits pancreatic carcinoma," Journal of Cellular and Molecular Medicine, vol. 13, no. 9b, pp. 40234033, 2009.

[106] C.-H. Wang, S.-H. Chiou, C.-P. Chou, Y.-C. Chen, Y.J. Huang, and C.-A. Peng, "Photothermolysis of glioblastoma stem-like cells targeted by carbon nanotubes conjugated with CD133 monoclonal antibody," Nanomedicine: Nanotechnology, Biology and Medicine, vol. 7, no. 1, pp. 69-79, 2011.
[107] W. Zhou, G. Kallifatidis, B. Baumann et al., "Dietary polyphenol quercetin targets pancreatic cancer stem cells," International Journal of Oncology, vol. 37, no. 3, pp. 551-561, 2010.

[108] P. H. Nguyen, J. Giraud, C. Staedel et al., "All-trans retinoic acid targets gastric cancer stem cells and inhibits patientderived gastric carcinoma tumor growth," Oncogene, vol. 35, no. 43, pp. 5619-5628, 2016.

[109] T. Ishiwata, K. Teduka, T. Yamamoto, K. Kawahara, Y. Matsuda, and Z. Naito, "Neuroepithelial stem cell marker nestin regulates the migration, invasion and growth of human gliomas," Oncology Reports, vol. 26, no. 1, pp. 9199, 2011.

[110] K. Yamahatsu, Y. Matsuda, T. Ishiwata, E. Uchida, and Z. Naito, "Nestin as a novel therapeutic target for pancreatic cancer via tumor angiogenesis," International Journal of Oncology, vol. 40, no. 5, pp. 1345-1357, 2012.

[111] M. Han, M. Liu, Y. Wang et al., “Antagonism of miR-21 reverses epithelial-mesenchymal transition and cancer stem cell phenotype through AKT/ERK1/2 inactivation by targeting PTEN," PLoS One, vol. 7, no. 6, article e39520, 2012.

[112] S. G. S. Nagaraja, V. Krishnamoorthy, R. Raviraj, A. Paramasivam, and D. Nagarajan, "Effect of trichostatin a on radiation induced epithelial-mesenchymal transition in A549 cells," Biochemical and Biophysical Research Communications, vol. 493, no. 4, pp. 1534-1541, 2017.

[113] I.-H. Park, J. H. Kang, J. M. Shin, and H. M. Lee, "Trichostatin a inhibits epithelial mesenchymal transition induced by TGF- $\beta 1$ in airway epithelium," PLoS One, vol. 11 , no. 8, article e0162058, 2016.

[114] S.-H. Lee, G. N. Shen, Y. S. Jung et al., "Antitumor effect of novel small chemical inhibitors of snail-p53 binding in K-Ras-mutated cancer cells," Oncogene, vol. 29, no. 32, pp. 4576-4587, 2010.

[115] L. Lin, B. Hutzen, H. F. Lee et al., "Evaluation of STAT3 signaling in ALDH+ and ALDH+/CD44+/CD24- subpopulations of breast cancer cells," PLoS One, vol. 8, no. 12, article e82821, 2013.

[116] Y. Li, H. A. Rogoff, S. Keates et al., "Suppression of cancer relapse and metastasis by inhibiting cancer stemness," Proceedings of the National Academy of Sciences of the United States of America, vol. 112, no. 6, pp. 1839-1844, 2015.

[117] T. Yamashita, M. Honda, K. Nio et al., "Oncostatin m renders epithelial cell adhesion molecule-positive liver cancer stem cells sensitive to 5-fluorouracil by inducing hepatocytic differentiation," Cancer Research, vol. 70, no. 11, pp. 46874697, 2010.

[118] J. S. Yakisich, N. Azad, V. Kaushik, G. A. O’Doherty, and A. K. V. Iyer, "Nigericin decreases the viability of multidrug-resistant cancer cells and lung tumorspheres and potentiates the effects of cardiac glycosides," Tumour Biology, vol. 39, no. 3, 2017. 


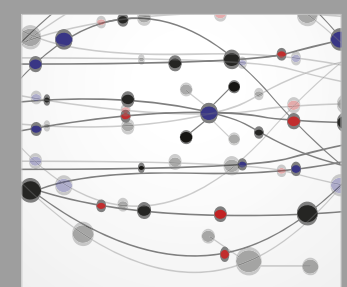

The Scientific World Journal
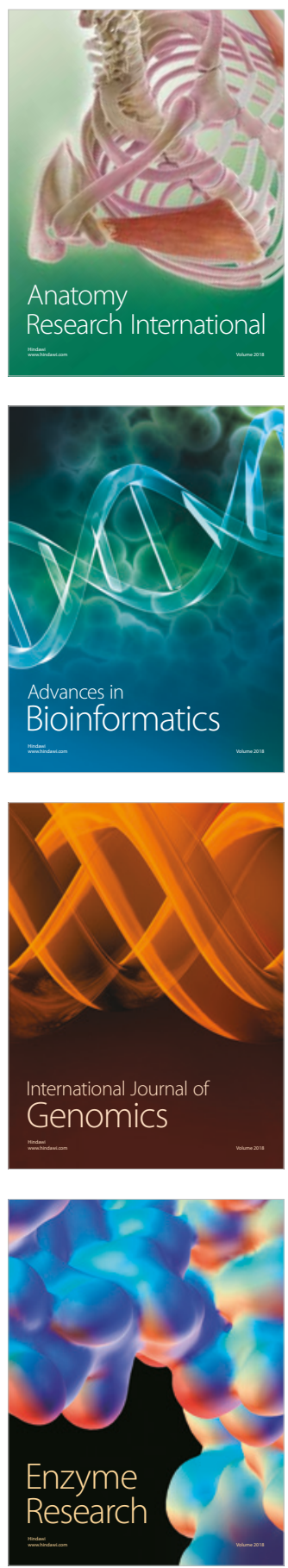
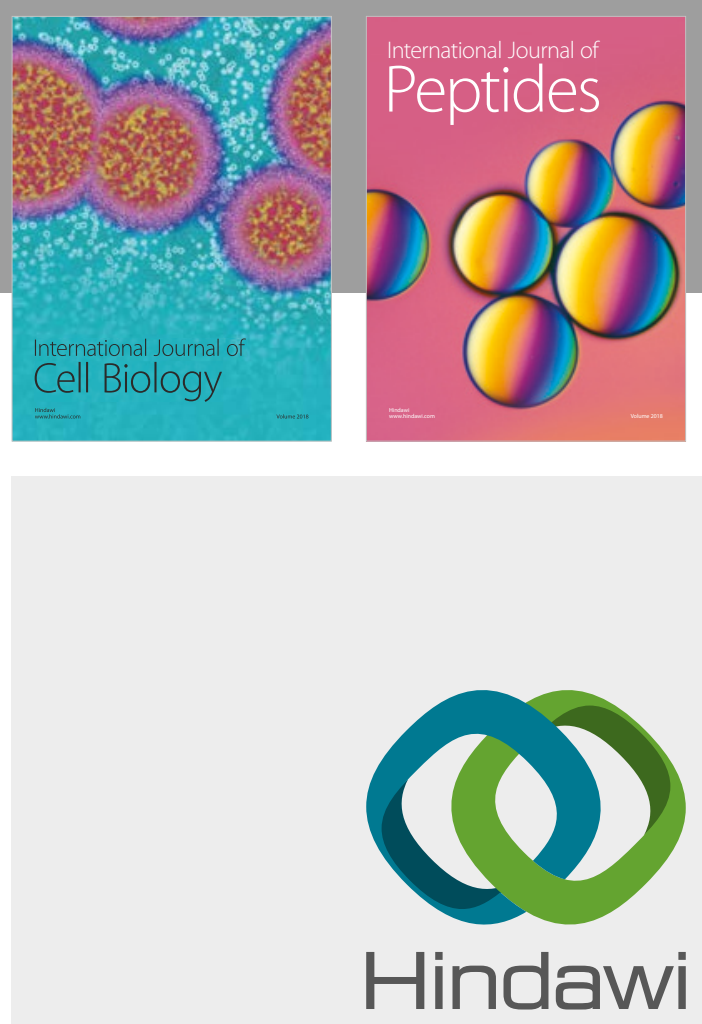

Submit your manuscripts at

www.hindawi.com
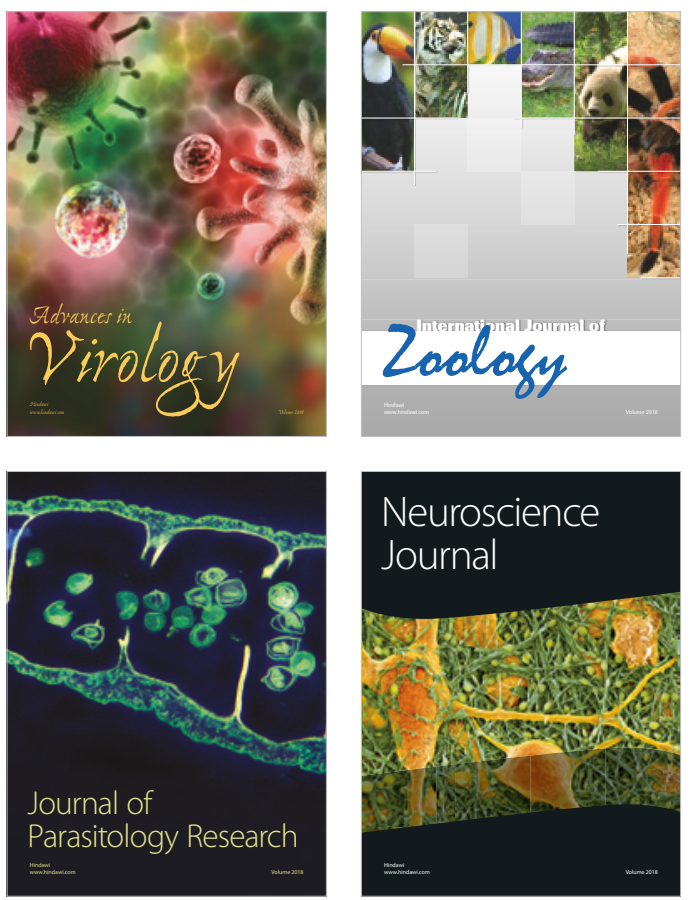
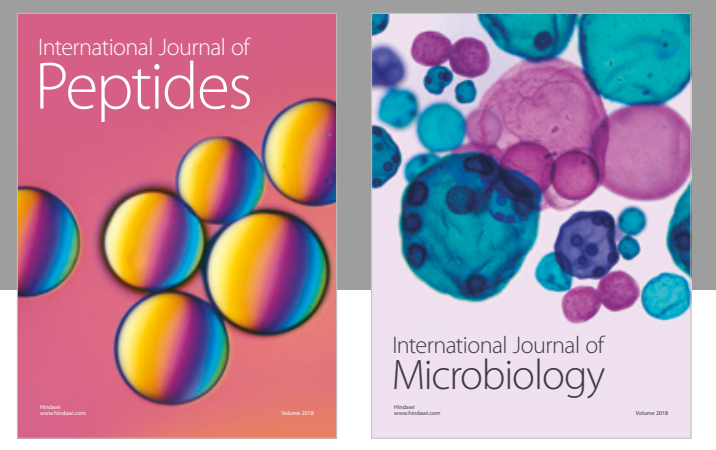

nternational Journal of Microbiology
Journal of
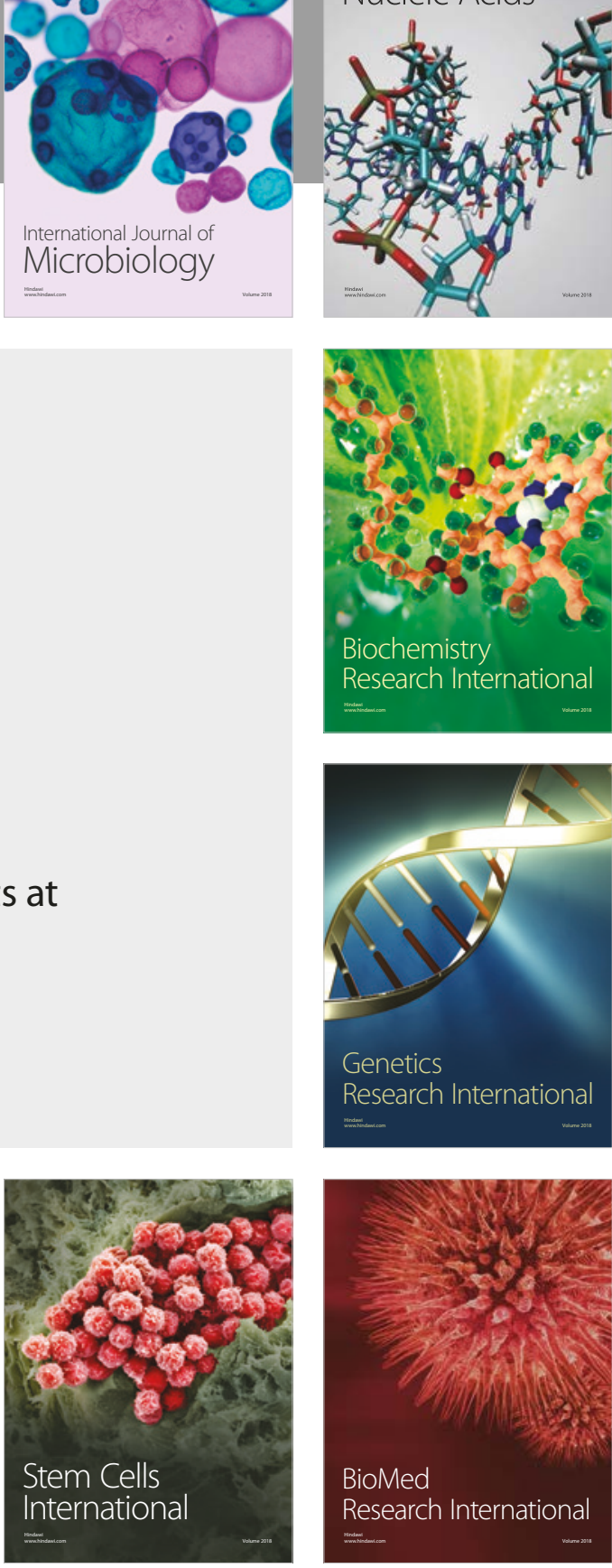
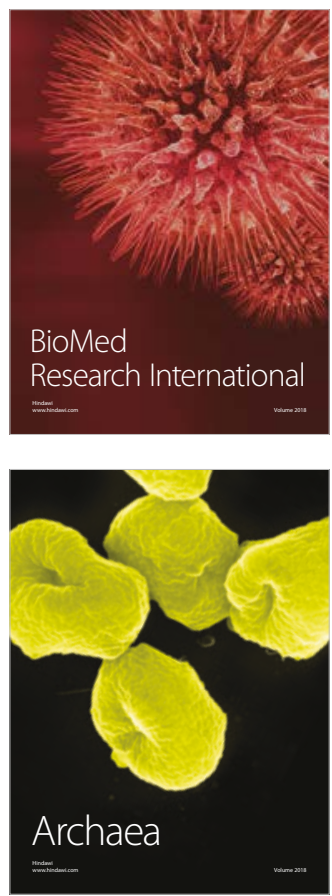